Tropical Journal of Pharmaceutical Research February 2017; 16 (2): 477-482

ISSN: $1596-5996$ (print); 1596-9827 (electronic)

(C) Pharmacotherapy Group, Faculty of Pharmacy, University of Benin, Benin City, 300001 Nigeria.

All rights reserved.

Available online at http://www.tjpr.org

Original Research Article

http://dx.doi.org/10.4314/tjpr.v16i2.29

\title{
Diclofenac transdermal patch versus the sustained release tablet: A randomized clinical trial in rheumatoid arthritic patients
}

\author{
Peng-Gang Xu ${ }^{1 \star}$, Xi-Feng Lei ${ }^{2}$, Bao-Di Ren ${ }^{1}$, Shui-Ying Lv' ${ }^{1}$ and Jun-Li Zhang ${ }^{1}$ \\ ${ }^{1}$ Department of Rheumatism, ${ }^{2}$ Department of Orthopedics, Xi 'an No. 5 Hospital, Xi'an, Shaanxi 710082, China
}

*For correspondence: Email: xupenggang2919@hotmail.com; Tel/Fax: 0086-537-2253157

Received: 10 March 2016

Revised accepted: 3 January 2017

\begin{abstract}
Purpose: To prepare and characterize transdermal films of diclofenac diethanolamine as a safer and more effective alternative than the sustained release (SR) tablet equivalent for prolonged relief from pain and inflammation in arthritis.

Methods: Transdermal films of diclofenac were prepared using sodium carboxymethyl cellulose and polyvinyl pyrrolidone K30, with turpentine oil and sesame oil as penetration enhancers. The films were characterized for physicochemical properties and for ex vivo permeation in a randomized clinical trial $(R C T)$ for analgesic activities in arthritic patients.

Results: The transdermal films were uniform in weight and thickness, flat, with high drug content (94.40 \pm 1.04 to $98.62 \pm 1.08 \%)$ and with high folding endurance $(149 \pm 9.09$ to $192 \pm 10.12)$. Drug permeation through excised rat abdominal skin was prolonged. Films containing penetration enhancers showed higher ex vivo drug permeation than those without the enhancer; furthermore, drug permeation increased with increase in the concentration of enhancer. The films were non-irritating to the skin. In $R C T$, F3 (containing turpentine oil, $1 \% \mathrm{v} / \mathrm{w}$ ) decreased the pain score from $9.87 \pm 1.14$ to $4.94 \pm 0.78$ units, compared with the SR tablet (once daily) which decreased pain from $9.59 \pm 0.42$ to $6.49 \pm 1.20$ units, $48 \mathrm{~h}$ post-administration. Turpentine oil showed better permeation enhancement than sesame oil in the transdermal films.

Conclusion: Transdermal films of diclofenac, formulated with permeation enhancers, may have greater therapeutic advantages over conventional oral tablets in terms of prolonged release and improvement of patient compliance in rheumatoid arthritis.
\end{abstract}

Keywords: Analgesic activity, Diclofenac, Permeation enhancer, Rheumatoid arthritis, Transdermal films

Tropical Journal of Pharmaceutical Research is indexed by Science Citation Index (SciSearch), Scopus, International Pharmaceutical Abstract, Chemical Abstracts, Embase, Index Copernicus, EBSCO, African Index Medicus, JournalSeek, Journal Citation Reports/Science Edition, Directory of Open Access Journals (DOAJ), African Journal Online, Bioline International, Open-J-Gate and Pharmacy Abstracts

\section{INTRODUCTION}

Rheumatoid arthritis (RA), an autoimmune and progressive systemic inflammatory disease, affects a huge number of people worldwide. RA adversely affects the quality of life and normal function, especially 10 years post-diagnosis. The immune system attacks joint tissues and potentially other body parts for unknown causes.
RA is characteristically associated with fatigue, chronic joint pain, and prolonged stiffness (even after rest) $[1,2]$. Although there is no cure for RA, novel effective drugs are being explored and are available to treat the disease and prevent joint deformities [3,4]. Managing the moderate to severe chronic pain and inflammation, as well as improving the quality of life in arthritic patients, is the most challenging and important goal of anti- 
arthritic therapy. Non-steroidal anti-inflammatory drugs (NSAIDs) are prescribed frequently for the management of pain and local inflammation (similar to gout) [5].

Conventional oral administration of NSAIDs is associated with serious adverse effects such as gastrointestinal (Gl) bleeding, renal dysfunction, blood pressure elevation, and significant plasmadrug level fluctuations, increasing the risk of overdose. Among the side effects reported, upper GI bleeding and GI toxicity are the most common [6]. Moreover, a high dosing frequency is desired for the majority of NSAIDs to provide prolonged relief from pain and inflammation.

To overcome these limitations, various novel approaches of drug delivery for NSAIDs have been investigated. Topical or transdermal drug delivery of NSAIDs is one of the most widely investigated and is a potential alternative for delivering NSAIDs. For the management of pain and inflammation in RA, localized drug delivery with polymeric dosage forms and delivery systems such as gels/creams/ointments, implants/in situ gels, and transdermal patches can deliver the drug in microenvironments of the bones, joints, or affected tissue and ligaments. The topical or transdermal drug delivery of NSAIDs has many advantages, such as localized/higher site specific delivery, prolonged drug release, avoidance of hepatic first pass, no gastric discomfort side effects, no interaction with the other drugs in multi-drug therapies, and better patient compliance [7,8]. Factors such as cytokines, prostaglandins including cyclooxygenase-2, and leukotrienes are regulated by activation of the transcription factor nuclear factor- $\mathrm{KB}$ and mediate pain and inflammation in RA. Therefore, any drug that can suppress the expression of tumor necrosis factor- $\alpha$ or suppress the activation of NF-KB may be a potential anti-arthritic drug [9].

Diclofenac is an NSAID used for the effective management of RA. Diclofenac, a carboxylic acid derivative, acts as a selective COX-2 inhibitor and is the most widely used NSAID for managing pain and inflammation after orthopedic injury/fracture, arthritis, toothache, and dysmenorrhea. Studies have reported that the efficacy of diclofenac (even at a low dosage of $100 \mathrm{mg} /$ day) is as effective as other newer analgesics used in arthritis. Diclofenac shows GI irritation, peptic ulceration, and Gl bleeding. Diclofenac also has a short half-life $(4 \mathrm{~h})$. The poor water solubility of diclofenac leads to poor dissolution and low bioavailability $[10,11]$.
Among the various transdermal drug delivery systems, transdermal films/patches are the most recently developed dosage forms, which are well-suited for chronic pain and inflammation management of arthritic patients [12]. An ideal transdermal patch should have flexibility, elasticity, and softness. However, at the same time it must have sufficient strength to follow the body contours. It must also possess good adhesive strength for prolonged retention on the skin for the desired duration of action. The use of various permeation enhancers can improve drug flux across the skin. In addition, various chemicals are used to improve penetration across the skin, including alcohols, terpenes, and surfactants $[13,14]$.

Therefore, the present study aims to develop and characterize transdermal films of diclofenac using two different permeation enhancers (in two different concentrations). For topical use, the diethanolamine salt of diclofenac is preferred over potassium or sodium salt. Thus, diclofenac diethanolamine was used in this report. Among the permeation enhancers, sesame oil and turpentine oil were used. The performance of the prepared films was compared with that of those without enhancer. The prepared films were characterized for various physicochemical parameters and for in vivo anti-arthritic activity.

\section{EXPERIMENTAL}

\section{Materials}

Diclofenac diethanolamine, sodium carboxymethyl cellulose (SCMC)-low viscosity grade, polyvinyl pyrrolidone K-30 (PVP-K30), turpentine oil, sesame oil, and carrageenan were purchased from Sigma Aldrich, USA. All other chemicals were of analytical grade.

\section{Preparation of diclofenac transdermal films}

Matrix type transdermal films loaded with diclofenac were prepared using the solvent evaporation technique (Table 1).

An aqueous solution of polyvinyl alcohol (4 $\% \mathrm{w} / \mathrm{v}$ ) was used to prepare the backing membrane. The aqueous solution of polyvinyl alcohol (PVA) was poured onto flat bottom teflon molds, followed by drying at $45^{\circ} \mathrm{C}$ for $3 \mathrm{~h}$.

The required amount of polymers (SCMC and PVP K-30) was dissolved in distilled water with constant stirring at $300 \mathrm{rpm}$. Diclofenac (drug), propylene glycol (plasticizer), turpentine oil, and sesame oil (as permeation enhancers) were added to this solution with continuous stirring. 
Table 1: Composition of the transdermal diclofenac patch

\begin{tabular}{llllll}
\hline Ingredient & \multicolumn{5}{c}{ Formulation } \\
\hline & F1 & F2 & F3 & F4 & F5 \\
\hline Diclofenac Diethanolamine $(\% \mathrm{w} / \mathrm{w})^{*}$ & 15 & 15 & 15 & 15 & 15 \\
SCMC: PVP $^{* *}$ & $1: 1$ & $1: 1$ & $1: 1$ & $1: 1$ & $1: 1$ \\
Di-n-butylphthalate $(\% \mathrm{w} / \mathrm{w})^{*}$ & 30 & 30 & 30 & 30 & 30 \\
Turpentine oil $(\% \mathrm{v} / \mathrm{w})$ & - & 0.5 & 1.0 & - & - \\
Sesame oil $(\% \mathrm{v} / \mathrm{w})$ & - & - & - & 0.5 & 1.0 \\
\hline
\end{tabular}

* \% W/w of total weight of polymer; ${ }^{* *}$ total weight of polymers taken was $500 \mathrm{mg}$

After uniform mixing, the solution was added to the backing membrane and kept on a flat surface. These flat bottom teflon molds containing drug-polymer solution were kept at 40 ${ }^{\circ} \mathrm{C}$ for $12 \mathrm{~h}$ in a hot air oven. The prepared cast film was cut into transdermal patches of $2 \times 2$ $\mathrm{cm}$, packed properly, and then stored in a desiccator until further use.

\section{Physicochemical characterization of prepared films}

The films were evaluated for thickness, weigh uniformity, folding endurance, and drug content. The average thickness (of three different sites) of the film was determined using a screw-gauge in a circular cast $(n=3)$. The weight of each patch $\left(5 \mathrm{~cm}^{2}\right)$ was determined $(\mathrm{n}=3)$. Folding endurance was determined by repeatedly folding a small strip $\left(2 \times 2 \mathrm{~cm}^{2}\right)$ of film at the same point until it broke.

For the determination of drug content, the patch from each film was dissolved in $100 \mathrm{~mL}$ of methanol with continuous stirring for $2 \mathrm{~h}(\mathrm{n}=3)$. The solutions were filtered, diluted (100 times), and analyzed spectrophotometrically (Perkin Elmer, Lambda 25, US).

\section{Ex vivo permeation studies}

The ex vivo permeation studies of the diclofenac films were performed in a modified Franz diffusion cell through excised rat abdominal skin. A patch of $2 \times 2 \mathrm{~cm}^{2}$ of each formulation was placed in close contact with excised skin. The receptor compartment of the diffusion cell was filled with $25 \mathrm{~mL}$ of $\mathrm{pH} 7.4$ phosphate buffer. The media was maintained at $37 \pm 1^{\circ} \mathrm{C}$ with agitation at $100 \mathrm{rpm}$. The samples (taken at different time intervals and with the same volume of fresh prewarmed media replaced in the receptor compartment) were analyzed spectrophotometrically.

\section{In vivo studies}

Healthy male Wistar rats (weight, 200-250 g) were used in the studies. The rats were kept in cages under standard environmental conditions of light and temperature and were allowed free access to drinking water and standard diet. Protocols of the animal study were approved by the Animal Ethical Committee (approval no. 2015/4.21) and the study was performed according to international guidelines [15].

\section{Primary skin irritation test}

For the primary skin irritation test, healthy male Wistar rats were divided into three groups of six rats each. A $4-\mathrm{cm}^{2}$ area of the dorsal portion of all rats was shaved and wiped with surgical spirit. The test formulation was applied over the respective test sites. The test sites were observed for any toxic side effects, erythema, and edema on the skin surface for $48 \mathrm{~h}$ after application in comparison to a standard irritant (2 $\%$ formalin solution) and control (blank film only).

\section{Clinical evaluation of selected films}

Patients in the orthopedic ward (OPD and IPD) with moderate pain due to RA were selected, and written consent of the patients was obtained for inclusion in the study. A total of 71 patients (40 male, 31 female) 49 to 65 years of age were selected for the clinical study. Three groups of 20 patients each were taken. Each group was administered one formulation (F1, F3 or F5). Eleven patients were kept on oral SR diclofenac (75 mg, po). The patients were randomized to receive drugs in a randomized crossover design, with a two-week washout period. Pain was assessed prior to treatment (baseline) and at 4, $12,24,48$, and $72 \mathrm{~h}$ after administration, using a 10 point visual analogue scale (VAS, 0 'no pain' to 10 'worst pain imaginable').

\section{Statistical analysis}

The results are expressed as the mean \pm standard deviation (SD) using Student's t-test and Origin 9 software. $P<0.02$ was considered statistically significant.

Trop J Pharm Res, February 2017; 16(2): 479 


\section{RESULTS}

The prepared transdermal patches of diclofenac were prepared and characterized. The effect of permeation enhancers was observed in the clinical studies.

\section{Physicochemical transdermal patches}

\section{characteristics}

of

The thickness, weight, folding endurance, and drug content of the prepared transdermal patches were determined (Table 2).

The weight of patches $\left(4 \mathrm{~cm}^{2}\right)$ of different formulations ranged from $114 \pm 0.40$ to $132 \pm$ $0.24 \mathrm{mg}$. All transdermal films showed uniform thickness ranging from $0.245 \pm 0.110$ to $0.298 \pm$ $0.048 \mathrm{~mm}$. Folding endurance ranged from $149 \pm$ 9.09 to $192 \pm 10.12$. All transdermal films showed high and uniform drug content (ranging from $94.40 \pm 1.04$ to $98.62 \pm 1.08 \%$ ).

\section{Ex vivo permeation}

Ex vivo permeation across the rat abdominal skin was increased with the use of permeation enhancers (Figure 1).

The percent drug permeated was increased with a high proportion of permeation enhancers, with the best permeation shown by F3 (with turpentine oil). At the end of the $24 \mathrm{~h}$ study, the drug permeation was 45.48, 58.89, 65.54, 56.29, and $60.50 \%$ for formulation F1, F2, F3, F4 and $\mathrm{F} 5$, respectively. It was evident that the permeation effect of turpentine oil was better than that of sesame oil.

\section{Primary skin irritation}

The use of the patch did not show any erythema and edema at the site of application based on primary skin irritation tests (after $48 \mathrm{~h}$ ). Thus, the patches were considered non-irritating to the skin.

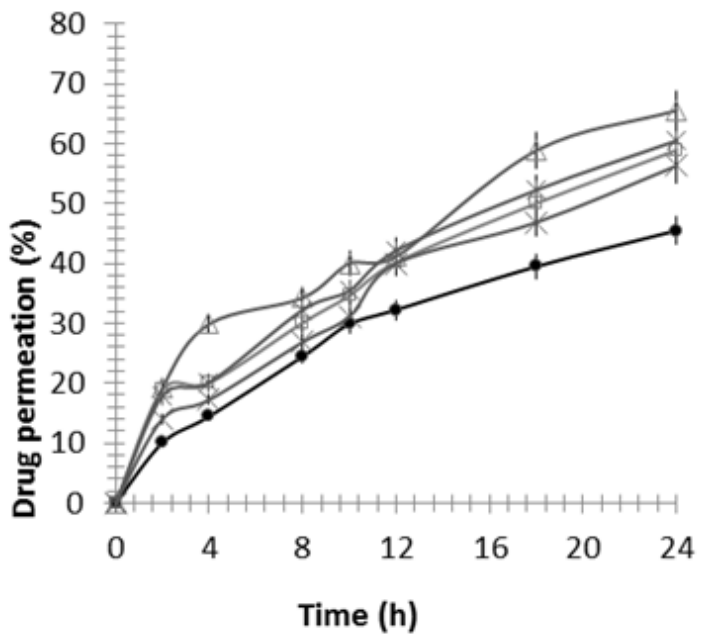

Figure 1: Ex vivo drug permeation of diclofenac in $\mathrm{pH}$ 7.4 phosphate buffer in a modified Franz diffusion cell


F3 - $\Delta-$; F4 -x- and F5 -* .

\section{Clinical analgesic effectiveness}

The VAS score of pain was studied in RA patients suffering from moderate to severe pain (pain score of 9 and above). The formulations F1, F3, and F5 were selected to study the effectiveness compared with the analgesic effect of the diclofenac sustained release (SR) tablet with VAS, which ranges from 0 'no pain' to 10 'worst pain imaginable'. The pain score decreased continuously with the formulation containing permeation enhancers (F3 and F5). F3 decreased the pain score from $9.87 \pm 1.14$ to $4.94 \pm 0.78$, while the SR tablet (once daily) decreased the pain score from $9.59 \pm 0.42$ to $6.49 \pm 1.20$, 48-h post-administration (Figure 2).

It was also noted that during the initial hours of the study, the SR tablet group showed better analgesia compared with the F1, F3, and F5 groups. However, once the lag time was over and the drug started to diffuse properly across the skin, the patches group showed better activity. Moreover, the SR tablet was administered daily (once) while the patches were applied once to the subject under study.

Table 2: Physicochemical evaluation of transdermal films of diclofenac diethanolamine

\begin{tabular}{lcccc}
\hline Formulation & $\begin{array}{c}\text { Weight } \\
(\mathbf{m g})\end{array}$ & $\begin{array}{c}\text { Thickness } \\
(\mathbf{m m})\end{array}$ & $\begin{array}{c}\text { Folding } \\
\text { endurance }\end{array}$ & $\begin{array}{c}\text { Drug loading } \\
(\%)\end{array}$ \\
\hline F1 & $114 \pm 0.40$ & $0.245 \pm 0.110$ & $149 \pm 9.09$ & $98.50 \pm 0.96$ \\
F2 & $124 \pm 0.20$ & $0.272 \pm 0.012$ & $184 \pm 12.06$ & $98.62 \pm 1.08$ \\
F3 & $125 \pm 0.04$ & $0.270 \pm 0.20$ & $190 \pm 10.40$ & $94.40 \pm 1.04$ \\
F4 & $129 \pm 0.24$ & $0.298 \pm 0.048$ & $179 \pm 9.20$ & $98.01 \pm 1.08$ \\
F5 & $127 \pm 0.20$ & $0.280 \pm 0.009$ & $192 \pm 10.12$ & $97.98 \pm 1.28$ \\
\hline
\end{tabular}






Figure 2: Pain score on the visual analogue scale (VAS) after application of the diclofenac patch in comparison with the diclofenac SR tablet $(75 \mathrm{mg}$ ); formulation F1 (without permeation enhancer), F3 (with turpentine oil $1 \%$ $\mathrm{v} / \mathrm{w}$ as permeation enhancer), and F5 (with sesame oil $1 \% \mathrm{v} / \mathrm{w}$ as permeation enhancer); the VAS ranges from 0 'no pain' to 10 'worst pain imaginable'

\section{DISCUSSION}

The topical or transdermal delivery of drugs to patients with RA is known to improve patient compliance with immediate and prolonged release of the drug [4-6]. The use of a single patch for the whole day is expected to be more patient friendly compared with frequent oral dosing of tablets. As far as drug release was concerned, the permeation enhancers or the penetration enhancers play an important role in accelerating drug release across the skin (when included in the transdermal delivery systems). Transdermal delivery of drugs can be enhanced using chemical enhancers, iontophoresis, electroporation, ultrasound, microneedles, jet injection, and thermal poration $[13,14,16,17]$. Of these various methods of transdermal enhancement of drug permeation, the use of chemical enhancers is the best method of increasing transport across the skin. The method is simple to adopt and cost-effective.

In this study, turpentine oil increased the permeation significantly compared with that of sesame oil. The increase was directly proportional to the concentration of turpentine oil and was in good agreement with previous studies [18-20]. Several groups have also reported turpentine oil and terpene-based enhancers as promising penetration enhancers with a greater effect on increasing the flux and anti-inflammatory activity [21,22]. The present study also found turpentine oil to be an effective penetration enhancer for transdermal drug delivery of diclofenac in the clinical study for films with penetration enhancers (F3 and F5), compared with that of films without enhancer (F1). The increasing concentration showed increased flux and increased analgesia.

The data obtained from the clinical study also supported the ex vivo permeation study results. Thus, the enhanced permeation of drug across the skin showed greater analgesic activity, thus, providing a greater benefit to those with RA.

\section{CONCLUSION}

The findings of this study reveal that turpentine oil and sesame oil are effective permeation enhancers in diclofenac transdermal films for use in patients with RA. However, turpentine oil is a better permeation enhancer than sesame oil. The results also show that the transdermal films of diclofenac with permeation enhancers may have greater therapeutic advantages over oral diclofenac tablets in terms of safety, prolonged release and improvement in patient compliance in RA.

\section{DECLARATIONS}

\section{Acknowledgement}

The authors would like to thank Xi'an No. 5 Hospital, Xi'an, China for providing the necessary facilities for the work.

\section{Conflict of Interest}

No conflict of interest associated with this work. 


\section{Contribution of Authors}

The authors declare that this work was done by the authors named in this article and all liabilities pertaining to claims relating to the content of this article will be borne by them.

\section{Open Access}

This is an Open Access article that uses a funding model which does not charge readers or their institutions for access and distributed under the terms of the Creative Commons Attribution License (http://creativecommons.org/licenses/by 14.0) and the Budapest Open Access Initiative (http://www.budapestopenaccessinitiative.org/rea d), which permit unrestricted use, distribution, and reproduction in any medium, provided the original work is properly credited.

\section{REFERENCES}

1. Lu K, Wang $H Z$, Gao YJ, Zhu J. Development and evaluation of aceclofenac loaded lipospheres for the treatment of osteoarthritis. J Biomater Tissue Eng 2015; 5: 504-508.

2. Perrot S. Should we switch from analgesics to the concept of "pain modifying analgesic drugs (PMADS)" in osteoarthritis and rheumatic chronic pain conditions? Pain 2009; 146: 229-230.

3. Chen $Y, L v H, D u Y P, W u$ J. Polyherbal gel as an alternative herbal treatment for arthritis: physical and in vivo characterization. J Biomater Tissue Eng 2015; 5: 342-346.

4. Zheng LJ, Yang L, Wang ZY, Chen CJ, Su YL. Preparation, in vitro, and in vivo characterization of thermosensitive transdermal hydrogel for arthritis. J. Biomater. Tissue Eng 2015; 5: 818-821.

5. Dray $A$. New horizons in pharmacologic treatment for rheumatic disease pain. Rheum Dis Clin N Am 2008; 34 . 481-505.

6. Semalty $A$, Semalty $M$, Rawat BS, Singh D, Rawat MSM. Development and physicochemical evaluation of pharmacosomes of diclofenac, Acta Pharm 2009; 59. 335-344.

7. Heyneman CA, Lawless-Liday C, Wall GC, Oral versus topical NSAIDs in rheumatic diseases: a comparison. Drugs 2000; 60(3): 555-567.

8. Stanos SP, Galluzzi KE. Topical therapies in the management of chronic pain. Postgrad Med 2013; 125(4): 25-33.

9. Yang CL, Or TC, Ho MH, Lau AS, Scientific basis of botanical medicine as alternative remedies for rheumatoid arthritis. Clin Rev Allergy Immunol 2013; 44(3): 284-300.

10. Parsaee S, Sarbolouki MN, Parnianpour M. In vitro release of diclofenac diethylammonium from lipid-based formulations. Int J Pharm 2002; 241(1): 185-190.

11. Van Walsem A, Pandhi S, Nixon RM, Guyot $P$, Karabis $A$, Moore RA, Relative benefit-risk comparing diclofenac to other traditional non-steroidal anti-inflammatory drugs and cyclooxygenase-2 inhibitors in patients with osteoarthritis or rheumatoid arthritis: a network metaanalysis. Arthritis Res Ther 2015; 17(1): 66-79.

12. Tanner $T$, Marks $R$. Delivering drugs by the transdermal route: review and comment. Skin Res. Technol 2008; 14: 249-260.

13. Kumar R., Philip A., Modified transdermal technologies: breaking the barriers of drug permeation via the skin, Trop J Pharm Res 2007; 6(1): 633-644.

14. Marwah H, Garg T, Goyal AK, Rath G. Permeation enhancer strategies in transdermal drug delivery. Drug Deliv 2014; 9: 1-15.

15. European Commission [homepage on the internet]. Directive 2010/63/EU on the protection of animals used for scientific purposes [cited 2014 August 12]. Available from: http://ec.europa.eu/environment/chemicals/lab_ animals/legislation_en.htm.

16. Rizwan M, Aqil M, Talegaonkar S, Azeem A, Sultana $Y$, Ali A. Enhanced transdermal drug delivery techniques: an extensive review of patents. Recent Pat Drug Deliv Formul 2009; 3(2): 105-124.

17. Ahad A, Aqil M, Kohli K, Chaudhary H, Sultana Y, Mujeeb $M$, Talegaonkar S. Chemical penetration enhancers: a patent review. Expert Opin Ther Pat 2009; 19(7): 969988.

18. Khan NR, Khan GM, Khan AR, Wahab A, Asghar MJ, Akhlaq $M$, Hussain A. Formulation, physical, in vitro and ex vivo evaluation of diclofenac diethylamine matrix patches containing turpentine oil as penetration enhancer. African J Pharm Pharmacol 2012; 6: 434-439.

19. Wang $Y$, Zhao XP, Ruan JW, Transdermal drug delivery system of aceclofenac for rheumatoid arthritis and the effect of permeation enhancers: in vitro and in vivo characterization, Int J Pharmacol 2015; 11: 456-462.

20. Wang Fu-Liang, Ji Hong-Mei, Zha Jian-You, Xu Gui-Jun, Guan Yu-Zhong. Chen Ye-Jun. Penetration enhancement effect of turpentine oil on transdermal film of ketorolac. Trop J Pharm Res 2015; 14(8): 1341-1348.

21. Varman RM, Singh $S$. Investigation of effects of terpene skin penetration enhancers on stability and biological activity of lysozyme. AAPS PharmSciTech 2012; 13(4): 1084-1090.

22. Yang Z, Teng $Y$, Wang $H$, Hou $H$. Enhancement of skin permeation of bufalin by limonene via reservoir type transdermal patch: formulation design and biopharmaceutical evaluation. Int J Pharm 2013; 447(12): $231-240$. 